\title{
El turismo recreativo en la Ciudad de MÉXICO: PERSPECTIVAS POST-COVID-19
}

\author{
Recreational tourism in Mexico City: post-Covid-19 perspectives
}

\author{
Cristina Oehmichen \\ Instituto de Investigaciones Antropológicas de la UNAM \\ cristina.oehmichen@gmail.com \\ ORCID https://orcid.org/0000-0002-4223-3668
}

RESUMEN: La pandemia del Covid-19 marcó un hito en la historia del turismo debido a que los procesos de globalización y compresión espacio-temporal que se habían registrado en los últimos 75 años, fueron suspendidos. Para diversos estudiosos, la desglobalización temporal ofrece una oportunidad para reflexionar sobre las propuestas de un desarrollo futuro del turismo más armónico, democrático y respetuoso de las sociedades anfitrionas y del medio ambiente. En este artículo se reflexiona en torno al turismo recreativo como una alternativa viable para el desarrollo del turismo en las ciudades y como una propuesta para salir de la crisis provocada por la pandemia. Para ello, se analizan algunos aspectos característicos del turismo recreativo desarrollados en el Centro Histórico de la Ciudad de México antes y durante la pandemia. Para guiar el análisis, se recupera el planteamiento de Darbellay y Stock (2012) sobre el "giro recreativo" del turismo en las ciudades, así como las propuestas que apuntan al desarrollo del turismo creativo y regenerativo, en el cual los visitantes tienen experiencias culturales más activas y participativas, dando cabida a una relación más cercana entre visitantes y anfitriones.

Palabras Clave: turismo cultural; covid-19; giro recreativo; turismo creativo; turismo regenerativo.

RESUM: La pandèmia del Covid-19 va marcar una fita en la història del turisme pel fet que els processos de globalització i compressió espaciotemporal que s'havien registrat en els últims 75 anys, van ser suspesos. Per a 
diversos estudiosos, la desglobalització temporal ofereix una oportunitat per a reflexionar sobre les propostes d'un desenvolupament futur del turisme més harmònic, democràtic i respectuós de les societats amfitriones i del medi ambient. En aquest article es reflexiona al voltant del turisme recreatiu com una alternativa viable per al desenvolupament del turisme a les ciutats i com una proposta per a eixir de la crisi provocada per la pandèmia. Per a això, s'analitzen alguns aspectes característics del turisme recreatiu desenvolupats en el Centre Històric de la Ciutat de Mèxic abans i durant la pandèmia. Per a guiar l'anàlisi, es recupera el plantejament de Darbellay i Stock (2012) sobre el "gir recreatiu" del turisme a les ciutats, així com les propostes que apunten al desenvolupament del turisme creatiu i regeneratiu, en el qual els visitants tenen experiències culturals més actives i participatives, donant cabuda a una relació més pròxima entre visitants i amfitrions.

Paraules clau: turisme cultural; covid-19; gir recreatiu; turisme creatiu; turisme regeneratiu.

ABSTRACT: The Covid-19 pandemic marks a milestone in the history of tourism due to the suspension of the processes of globalization and space-time compression witnessed over the last 75 years. Various scholars have grasped the opportunity offered by this temporary deglobalization to examine proposals for a more harmonious, democratic and respectful future development of tourism for the host societies and the environment. This article reflects on recreational tourism as a viable alternative for the development of tourism in cities and as a proposal to overcome the crisis caused by the pandemic. To this end, some characteristic aspects of recreational tourism developed in Mexico City's historic centre before and during the pandemic are analyzed. The analysis is guided by Darbellay and Stock's (2012) approach to the "recreational turn" of tourism in cities, and by proposals for developing creative and regenerative tourism, in which visitors have more active and participatory cultural experiences, allowing for a closer relationship between visitors and hosts.

KeYWORDS: cultural tourism; covid-19; recreational turn; creative tourism; regenerative tourism. 


\section{Introducción}

Q1 surgimiento del Sars-Cov-2, anunciado por primera vez en diciembre de 2019 en Wuhan, China, ha golpeado fuertemente al sistema turístico. Su rápida propagación está relacionada con la turistificación planetaria y la movilidad. En un recuento detallado, Murray y Cañada (2021) observan que la propagación inició con una turista de Wuhan llegó a Bangkok a principios de enero; después, dos turistas chinos que ya estaban contagiados, aterrizaban en Milán. Luego, de manera casi simultánea, un turista alemán llegaba a La Gomera y un británico aterrizaba en Mallorca, ambos en España. Los dos turistas tuvieron que ser hospitalizados. Poco después, un turista que había visitado Nepal fallecía en Valencia. En Estados Unidos, el virus llegó a Seattle en un vuelo procedente de Wuhan y, poco después, llegó a Nueva York con el arribo de turistas procedentes de Europa. La vinculación entre la propagación del Covid-19 y el turismo es evidente. Pero, añaden, los vectores “...no eran exclusivamente turistas chinos viajando por Europa, sino que se trataba de ejecutivos británicos, alemanes y suizos que habían visitado China en viajes de negocios" (Murray y Cañada 2021: 25).

En América Latina, la propagación del virus inició por el regreso de turistas de clase media y alta que habían visitado algún país europeo o vacacionado en Estados Unidos. De ahí que entre los sectores populares al principio se creyera que el Covid-19 era una enfermedad "de ricos", como ocurrió en México (Oehmichen y Escalona 2020).

La siguiente fase de propagación del Covid-19, fue la transmisión comunitaria que ocurre cuando el contagio se produce de manera local y no sólo por casos importados. Para el 15 de abril, el número de casos confirmados se acercaban a los 2 millones de personas, con más de 125.000 muertes en más de 200 países (Gössling, et al. 2021). Con este panorama de contagios, sin medicamentos ni vacuna para prevenir la enfermedad, la mayoría de los países buscaron contener la expansión del virus a través de diversas formas de intervención no farmacéutica, tales como la cuarentena, el distanciamiento social, cierre de escuelas, lugares de trabajo no esenciales, suspensión de congresos, reuniones masivas, festivales, entre otras. Se acudió a las mismas medidas que se adoptaron hace un siglo para contener la mal llamada "gripe 
española" (Gössling, et al. 2021). Desde luego, todas estas medidas afectaron la movilidad y, por ende, al turismo.

La pandemia del Covid-19 marca un hito en la historia del turismo debido a que los procesos de globalización y compresión espacio-temporal que se habían registrado en los últimos 75 años, fueron suspendidos (Niewiadomski 2020). Para diversos analistas, la desglobalización temporal ofrece a la industria turística una oportunidad para desarrollarse bajo los principios de sostenibilidad y acabar con varios de sus "lados oscuros", como son la degradación ambiental, la explotación económica, la dependencia o el hacinamiento (Niewiadomski 2020; Nepal 2020; Hall, et al. 2020; Duxbury et al. 2020). No obstante estas propuestas, hubo fuertes voces empresariales y políticas que presionan para que el turismo se abriera lo antes posible y se regresara a la "normalidad" sin realizar cambio alguno. A la vez, pedían subsidios para las empresas afectadas, sin necesariamente comprometerse a mitigar los efectos negativos del turismo sobre el medio ambiente (Hall et al. 2020).

La pandemia puso al descubierto las contradicciones de las políticas neoliberales y mostró las enormes desigualdades y la vulnerabilidad en que estaban colocados los distintos países del orbe. Los efectos de la pandemia en el sistema turístico han sido devastadores, pero han sido más fuertes para aquellos países emergentes que dependen altamente del turismo (Nepal 2020).

México tiene una fuerte dependencia del turismo, pues esta actividad constituye la tercera fuente de divisas que recibe y contribuye con el $8.7 \%$ del Producto Interno Bruto (PIB), cifra superior a lo que aportan otros sectores representativos de la economía, como son la industria de la construcción, los servicios financieros y de seguros, la fabricación de equipo de transporte, la minería y todo el sector primario (SECTUR 2020).

La pandemia ha representado un fuerte golpe para el turismo en México. En 2020, provocó la disminución de $47.5 \%$ de llegadas visitantes internacionales con respecto a 2019. Con ello disminuyeron las divisas procedentes del turismo en 55.1\% (SECTUR 2021). Estos efectos están desigualmente distribuidos, pues los destinos de sol y playa altamente dependientes del turismo internacional, como Cancún y la Riviera Maya, son más vulnerables 
que aquellos que dependen más del turismo doméstico y cuya economía está diversificada. Este es el caso de la Ciudad de México.

Este artículo tiene el objetivo de analizar el desarrollo del turismo recreativo en la Ciudad de México como un recurso para salir de la crisis provocada por la pandemia. Para ello, se analiza el caso del Centro Histórico para analizar algunas de sus características y problemáticas antes y durante la pandemia. Para guiar el análisis, se recupera el planteamiento de Darbellay y Stock (2012) sobre el "giro recreativo" del turismo en las ciudades, así como las propuestas que apuntan al desarrollo del turismo creativo y regenerativo (Richards 2001; Duxbury y Richards, 2019; Duxbury, et al. 2020).

\section{Metodología}

La metodología recupera el trabajo de campo realizado por la autora en el Centro Histórico en diferentes momentos entre 2015 y 2019 entre guías de turistas, promotores, residentes, organizaciones de indígenas migrantes y asentadas en la ciudad, trabajadores de restaurantes que residen en el esta demarcación. Durante la pandemia, la investigación se basó en 10 entrevistas virtuales aplicadas entre septiembre de 2020 y marzo de 2021 a residentes del Centro Histórico. Se hizo un seguimiento a la prensa escrita, particularmente a través del semanario Proceso y los periódicos La Jornada y El Universal. Se participó en redes vecinales durante la pandemia a través de Whatsapp y Facebook, lo que permitió una aproximación al tema a través de un ejercicio de etnografía digital.

\section{El turismo en la Ciudad de México}

La Ciudad de México (CDMX) es la capital del país. Cuenta con poco más de 9 millones de habitantes. Esta cifra se incrementa a casi 22 millones si se considera también a la Zona metropolitana del Valle de México (INEGI 2020). Esto hace a la CDMX una de las urbes más pobladas del mundo. Históricamente, esta ciudad ha sido un destino importante para un sinnúmero de viajeros. En el siglo XIX fue identificada con el nombre de la "Ciudad de los Palacios", título que se le atribuye al viajero inglés Charles Latrobe, quien la visitó en 1834 y después de recorrer las entonces llamadas "casas grandes 
de la ciudad" acuñó ese término (De Mauleón, 2015). En el siglo XXI, la conversión de la ciudad en una "marca" ha generado el branding comercial global con el que se promueve el turismo, ahora para reconocerla como la “Capital Cultural de América”, según la promoción realizada por el gobierno capitalino.

La CDMX es uno de los principales destinos turísticos del país. Tiene una infraestructura suficiente para albergar a los casi 14 millones de turistas. De ese total, poco más de 10 millones fueron turistas nacionales y el resto internacionales. En 2019, la ciudad contaba con 51,601 cuartos de hotel, y tuvo un promedio de 68\% de ocupación (Gobierno de la CDMX 2020/a). De acuerdo con la misma fuente, los hoteles y restaurantes, generaron en 2019, un total de 373,522 empleos directos y 933,805 indirectos.

Cuando llegó la pandemia del Covid-19, sin embargo, el número de turistas que llegaron a la CDMX se redujo drásticamente, al recibir en 2020 a sólo una tercera parte de lo que había tenido con respecto al año anterior, como puede apreciarse en el Cuadro 1.

Tabla I. Llegada de turistas hospedados en hoteles de la Ciudad de México 2019-2020.

\begin{tabular}{lll}
\hline Turistas & 2019 & 2020 \\
\hline Total & $13,905,859$ & $4,574,178$ \\
\hline Nacionales & $10,150,039$ & $3,457,4 \mathrm{II}$ \\
\hline Internacionales & $3,755,044$ & $\mathrm{I}, \mathrm{I} 16,767$ \\
\hline
\end{tabular}

Fuente: Elaboración propia con base en el Resumen de Indicadores Turísticos. Actividad Turística de la Ciudad de México enero - diciembre de 2010 - 2020. Secretaría de Turismo de la Ciudad de México, Dirección General de Competitividad Turística.

La reducción en el número de turistas hospedados hoteles repercutió en la reducción de la derrama económica que estos generan, al caer de 5,817.15 mdd $^{1}$ en 2019 a 1,818.88 mdd en 2020 (Gobierno de la CDMX 2020/b).

1. $m d d$ se refiere a millones de dólares americanos. 
La CDMX cuenta con diferentes sitios de atracción turística distribuidos por los diferentes puntos de la ciudad. Todos pueden ser visitados por los turistas. No obstante, aquí nos detendremos a explorar uno de sus lugares más representativos: el Centro Histórico.

\section{El Centro Histórico y el turismo cultural recreativo}

El Centro Histórico ofrece una amplia oferta cultural. En el se ubica el Palacio Nacional, donde pueden apreciarse los murales de Diego Rivera y otras obras de arte. Están las oficinas del gobierno de la ciudad. Se encuentra el sitio arqueológico del Templo Mayor, donde hay un museo de sitio, así como la Catedral Metropolitana, uno de los templos católicos más grandes de América Latina. También se encuentran el Palacio de Bellas Artes, el Museo Nacional de Arte, el Museo de la Ciudad de México, el Museo del Estanquillo, el Museo Franz Mayer, el Museo Interactivo de Economía, entre otros de en total de 45 museos. Cuenta además con corredores peatonales donde los visitantes pueden caminar para acudir a museos, iglesias, comercios, restaurantes o apreciar las joyas arquitectónicas, y acudir a recintos culturales. También se encuentra una amplia gama de restaurantes de todo tipo, desde los más elegantes hasta los más tradicionales y de precios accesibles.

A sus hoteles llegan quienes cuentan con suficientes recursos para hospedarse en el hotel Hilton ubicado frente a la Alameda Central, o en recintos gestionados por otras grandes cadenas, como Marriot, Holiday Inn, Four Seasons, Barceló, NH, Sheraton, entre otros. Pero hay también quienes prefieren hospedarse en un hotel mucho más económico. Hay también un uso creciente de rentas turísticas que se promueven a través de plataformas tipo Airbnb en lugares habitacionales donde la mercantilización de la vivienda se ha convertido en un negocio lucrativo.

En esta parte de la ciudad residen más de 260 mil habitantes. Los espacios habitacionales, sin embargo, ahora son utilizados también como espacios de renta de muy corto plazo. En los condominios hay propietarios que rentan su vivienda y la acondicionan para la renta vacacional. Es el caso, por ejemplo, de los condominios Puerta Alameda y Marroquí, ubicados a un costado de la Alameda Central. En dichos condominios el alquiler de viviendas a través 
del Airbnb y otras plataformas se multiplicó. Antes de la pandemia, en 2019, los vecinos calculan que alrededor del $30 \%$ de las viviendas era utilizada con fines turísticos.

Con la llegada de la pandemia, los turistas dejaron de llegar y alrededor de un tercio de las viviendas quedaron deshabitadas. Quienes se habían convertido en gestores de vivienda para usos turísticos, se quedaron sin empleo. Los inmuebles que rentaban, los devolvieron a sus dueños. Durante la pandemia, estas acciones fueron suspendidas de manera abrupta, afectando a comerciantes, restauranteros, hoteleros, rentistas y gestores del Airbnb.

El Centro Histórico contiene una amplia oferta cultural y gran dinamismo. Antes de la pandemia había desarrollado un "turismo recreativo" donde los espacios del turismo confluyen con la experiencia urbana de los habitantes de la ciudad. También se identifica con lo que algunos autores han denominado "turismo creativo", entendiendo por ello un tipo de turismo cultural en donde los visitantes buscan experiencias culturales más activas y participativas, dando cabida a una relación más cercana entre visitantes y anfitriones (Duxbury y Richards 2019).

\section{La diversidad de actores y la pluralidad cultural}

Al Centro Histórico acude una gran diversidad de personas: desde oficinistas, ejecutivos, políticos, periodistas, pasando por agencias de viajes, guías de turistas, artistas, vendedores de artesanías, músicos, bailarinas y, sobre todo, comerciantes formales e informales. También existe una gran cantidad de restaurantes, cafés, mesones para toda clase de gustos y bolsillos. Converge una enorme heterogeneidad de actores que se amplia con la llegada de turistas nacionales y extranjeros. Al centro han llegado en diferentes periodos inmigrantes de todo los estados de la República Mexicana, así como indígenas hablantes de náhuatl, mixteco, mazahua, triqui, otomí y zapoteco, principalmente. Hay residentes que proceden de países latinoamericanos que han instalado restaurantes con una amplia oferta gastronómica. También hay un número creciente de asiáticos entre los que destaca los que habitan en el barrio chino y, muy cerca de ahí, el barrio coreano. Con mayor antigüedad y 
tradición, se encuentra una fuerte presencia de descendientes de inmigrantes españoles que cuentan con más de 25 restaurantes en el Centro Histórico.

La afluencia en el Centro Histórico cambia según la hora, del día de la semana, y según la temporada del año. Durante el día sus calles son muy concurridas y en algunos tramos son intransitables dada la enorme cantidad de personas y vehículos que llegan, pero por la noche se convierten en calles semivacías. Esto nos habla de que aún a pesar de los esfuerzos repoblar el centro, éste sigue siendo un espacio más de comercios y de actividad administrativa que habitacional. A lo largo del año llegan turistas a la ciudad, pero es en los periodos vacacionales de Semana Santa, verano y diciembre cuando hay mayor presencia de visitantes locales y de turistas. El turismo interno e internacional acude al Centro Histórico para visitar museos, restaurantes, ir de compras, convivir con sus familiares o simplemente para pasear e invertir el tiempo libre en ocio creativo. Otros más realizan turismo religioso, siendo la religión el principal motivo de su visita.

Al respecto, podemos reflexionar sobre la existencia de un nuevo ecúmene que se produce a través de la domesticación turística del espacio originado por la confluencia heterogénea de grupos y personas que conviven en un mismo tiempo y espacio (Darbellay y Stock 2012). Los espacios que han sido "domesticados" en función del turismo, anteriormente tenían otros usos.

Con la llegada del Covid-19 los negocios cerraron: escuelas, oficinas y comercios permanecieron cerrados y solo se se mantuvieron abiertos los considerados como esenciales. Los restaurantes pudieron trabajar, pero sólo se les permitió vender comida para llevar. Esta situación implicó el despido o descanso por tiempo indefinido de trabajadores y empleados. Entre los cambios en la situación laboral de los trabajadores golpeados por la pandemia, destaca la multiplicación de repartidores de los más diversos productos que se compran en plataforma con entrega a domicilio. Otro reconfiguraron sus negocios y actividades económicas. Los artistas comenzaron a ofrecer espectáculos por zoom, bailarinas ofrecieron espectáculos a domicilio, los cocineros y chefs organizaron "cocinas ocultas" con puntos de venta ubicados en sitios que solo despachan a domicilio. Algunos ya operaban antes de la pandemia. Los inmigrantes indígenas que habitan en el Centro Histórico, ante la imposibilidad de trabajar, regresaron a sus pueblos. 
A pesar de las restricciones, las aglomeraciones y tumultos en las calles del Centro Histórico no terminaron por completo. A lo largo de 2020 y 2021 hubo momentos en que cientos de personas decidieron hacer caso omiso a la recomendación de las autoridades de quedarse en casa. Las calles se llenaron con la presencia de quienes iban a hacer sus compras de Navidad y Día de Reyes. Los vendedores ambulantes llenaron de nuevo las calles y entraron en conflicto con el comercio establecido y el gobierno de la ciudad. En 2020, por primera vez en la historia, los más de siete millones de personas que cada 12 de diciembre acuden al santuario de la Villa de Guadalupe, no pudieron ir a la peregrinación.

\section{El turismo en el giro recreativo}

Darbellay y Stock (2012) proponen una definición relacional del turismo que puede ser de utilidad para entender la dinámica del Centro Histórico como una relación entre personas, objetos y lugares. Definen la "mirada turística" no como percepción visual (propuesta hecha por Urry en The Tourist Gaze), sino como una codificación específica de prácticas sociales. Parten de definir las "dimensiones turísticas" como una relación entre personas, y de éstas con los objetos y las prácticas.

De acuerdo con esta propuesta, se considera que los turistas habitan los lugares de manera diferente a como lo hacen los residentes. Sin embargo, el giro recreativo ocurre cuando los habitantes de una ciudad realizan actividades similares a las que efectúan los turistas, utilizan el espacio urbano para disfrutar del tiempo libre, pasean, asisten a museos, restaurantes, conciertos y festivales.

En el Centro Histórico el giro recreativo del turismo se manifiesta en el consumo del espacio urbano por parte de los propios habitantes de la ciudad, quienes sin ser turistas realizan actividades lúdicas y recreativas en los espacios del turismo. El giro se produce cuando las dimensiones turísticas infunden prácticas y productos en la vida cotidiana de los habitantes locales. Es ahí donde la frontera entre lo turístico y lo no-turístico se desvanece, de la misma manera en que la línea que separa vida cotidiana y extra-cotidiana se difuminan. Desde esta perspectiva, el turismo puede ser 
interpretado también como un acto de semiosis social que pone en relación a personas con diferentes antecedentes (locales y culturales) que interactúan con diferentes formas de habitar los espacios y producir significados.

Se puede habitar la ciudad y al mismo tiempo disfrutar del "distanciamiento turístico". Posiblemente esta sea una perspectiva para un turismo post-pandémico en una nueva normalidad, acorde con el turismo de cercanías y el redescubrimiento de la propia ciudad en que se habita.

\section{La multilocalidad y las relaciones translocales}

Otra característica del giro recreativo del turismo, son las relaciones multilocales. En agosto de 2019 acompañé a una familia de turistas estadounidenses en su recorrido por diversos lugares de interés turístico de la CDMX. Pude observar relaciones y comportamientos que no hubiera visto si no hubiese estado acompañada por ellos. Mis invitados se relacionaban con los lugares a través de su descolocación corporal respecto a su lugar de origen (Chicago y Houston). Desde esta posición, tenían una especie de obsesión por acudir a la "Casa Azul", que es donde vivió Frida Kalho y adquirir artesanías que representaban a esta reconocida artista mexicana. Visitaban el Museo del Estanquillo y el Museo de Arte Popular. Tomaban fotos, se retrataban con la gente. Destinaron una tarde para comer a un restaurante oaxaqueño caro y consumir mezcal. Escuchaban la música mexicana y se retrataban con los músicos de Oaxaca, de Veracruz o de Jalisco. Conversaban con los vendedores ambulantes de artesanías, que también procedían de localidades diversas, de otros estados del país. Los artesanos parecían tener un sexto sentido para identificar a los turistas y sabían aproximarse a ellos para vender sus productos y lo logran con cierto éxito. La multilocalidad y las relaciones translocales no sólo eran producidas por los turistas y por los vendedores, sino por la interacción que se da entre ellos, los músicos, los artesanos y el escenario.

Hay una asociación entre prácticas y lugares donde se crean nuevas relaciones espaciales de convivencia. Mis visitantes "gringos" (como en México se les denomina a los estadounidenses) se retrataron frente a la Casa de los Azulejos y al lado del organillero. Todo ello, contribuía de alguna manera a actualizar una identidad cosmopolita, tanto para unos como para otros. Para 
los visitantes, ir al Centro Histórico representaba también la oportunidad de acudir al mercado de artesanías. Al día siguiente, los turistas estadounidenses por fin acudieron a la Casa - Museo de Frida Kalho, en Coyoacán, barrio ubicado en el sur de la ciudad. Junto con el Centro Histórico, Coyoacán forma parte de los "ethnoscapes" a los que se refiere Appadurai (1990), cuando se refiere a los paisajes de personas que constituyen el mundo cambiante: turistas, inmigrantes, población local, exiliados y otros grupos que contribuyen a la heterogeneidad, por medio de la cual los huéspedes y anfitriones remodelan las identidades.

Las casas de mis visitantes ubicadas en Houston y en Chicago, están decoradas con las más diversas artesanías mexicanas, más que las que los mexicanos solemos tener en nuestras casas. Ellos cuentan con una amplia colección de cerámicas, textiles, cuadros, vajillas, decorados navideños, nacimientos, entre otras muchas cosas adquiridas en sus visitas a México. Como citadina nacida en la Ciudad de México, yo no compraría tal cantidad de artesanías y, menos aún, un sombrero de charro, pero los visitantes sí lo hacen y lo disfrutan, pues en su lugar de origen dichos elementos constituyen símbolos de distinción y de reivindicación cultural. ¿Qué significa para ellos todo ese universo de artesanías mexicanas? ¿Reforzar una identidad "mexican-american" como una forma de distinción frente a otros estadounidenses que no salen de su país?. Aquí adquiere importancia la dimensión semiótica del viaje, la fotografía, la cocina, la artesanía, y el significado que puede contribuir a reforzar una identidad cosmopolita del visitante, pero también de los anfitriones.

\section{Las “turismodes" globales y el turismo creativo}

La globalización ha significado el surgimiento de lugares turísticos globalizados. Las "turismodes" globales de lugares están presentes en los distintos sitios de atracción turística de la CDMX. Ciertas imágenes del Centro Histórico se han difundido por todo el mundo: se han globalizado. Uno de los ejemplos más ilustrativos de este proceso, es la invención de una nueva tradición en Día de Muertos, donde miles de personas desfilan a manera de carnaval por las calles del Centro Histórico para conmemorar el Día de Muertos. Lo hacen disfrazados de calaveras. En su recorrido recorren siete 
kilómetros y a su paso por las calles céntricas portan ofrendas, flores, llevan carros alegóricos y comparsas

Esta nueva tradición inició en 2016, después de la exhibición de la cinta Spectre, de la saga hollywoodense de James Bond, que en algunos pasajes aparecen cientos de personas vestidas de calaveras que desfilan por las calles del Centro Histórico de la CDMX el 2 de Noviembre, que es el Día de Muertos. Este es un claro ejemplo de turismo creativo, entendiendo por ello la oportunidad que tienen turistas y visitantes de desarrollar su potencial creativo mediante la participación activa en experiencias características del lugar (Richards, 2001). Algo similar ocurrió con la película d dibujos animados Coco (2018), producida por Pixar y Disney, que ha hecho que los turistas vayan a las comunidades ribereñas del Lago de Pátzcuaro para visitar los lugares representados en la película. Por su parte, la población local produce objetos, artesanías y vestuarios que emulan los objetos y los personajes de que aparecen en el filme (Alvarado-Sizzo, et al. 2020).

La transversalidad del turismo hace posible la construcción de imaginarios que después se replican en otras prácticas sociales. En estos escenarios, los turistas participan activamente mediante la interacción entre disfrute y experiencia, toda vez que se convierten ellos mismos en actores (Nicosia 2018).

\section{Una diversidad extrema de prácticas y los derechos ciudadanos}

Otra dimensión del turismo recreativo consiste en la diversidad extrema de prácticas, pues se trata de un turismo no estandarizado debido a la amplia variedad de actividades que realizan los turistas en sus visitas y recorridos. En el Centro Histórico de la Ciudad de México se pueden hacer excursiones de turismo gastronómico, recorridos con visitas especializadas a restaurantes y bares, a zonas arqueológicas y sitios de interés histórico, recorridos por los templos, visitas a museos y galerías, además de que hay turismo de intereses especiales, tales como el turismo gay, el turismo de salud, entre otras formas especializadas de turismo.

El gobierno de la CDMX ha desarrollado una amplia promoción turística que busca atraer a los turistas de la comunidad lésbica, gay, bisexual, transgénero, travestis, transexuales e intersexuales (LGBTTTI) (Secretaría de 
Turismo 2020). La influencia del turismo, por un lado y la lucha por la defensa de los derechos ciudadanos, por parte de la población de la ciudad se integran y se recrean. En la Ciudad de México el matrimonio igualitario fue aprobado desde agosto de 2010 y la adopción homoparental es una práctica permitida y legal. Con estos antecedentes, la CDMX se ha mostrado ante el mundo como una ciudad amigable con las minorías sexuales.

López y Carmona (2008) señalan que en muchas ciudades de México han desarrollado una estrecha relación entre los espacios turísticos y los espacios gay. En gran parte, esto se debe a la tendencia de los espacios turísticos a aceptar las diferencias sociales y culturales y, consecuentemente, las de la sexualidad humana (Sánchez y López, 2000). La Ciudad de México, Puerto Vallarta, Guadalajara, Monterrey, Tijuana, Acapulco y Cancún, son las ciudades que cuentan con una amplia oferta de espacios asociados a negocios concurridos por turistas gay.

El reconocimiento del derecho a la diversidad sexual en la Ciudad de México ha avanzado por el camino de la inclusión. Los visitantes nacionales y extranjeros pueden disfrutar de una oferta amplia. Entre los servicios que se ofrecen, se encuentran conciertos, festivales, conferencias y exposiciones, que se organizan entre empresas, cámaras de comercio, organizaciones no gubernamentales y la ciudadanía.

Así como la comunidad LGBTTTI ha ido conquistando derechos, en la Ciudad de México las mujeres tienen el derecho de interrumpir el embarazo desde 2007, cuando se reformó el Código Penal para reconocer ese derecho que había sido exigido por las mujeres y el movimiento feminista. En los estados donde prima el conservadurismo, el aborto es penalizado, sobre todo en aquellas entidades gobernadas por el ultraconservador Partido Acción Nacional. Dada esta situación, es frecuente que las mujeres de dichos estados acudan a la Ciudad de México para interrumpir un embarazo no deseado, donde las instituciones de salud públicas las atienden de manera gratuita. Durante la pandemia, dichos servicios continuaron prestándose a todas las mujeres que lo solicitaron. 


\section{Más allá del Covid-19: el turismo regenerativo y de proximidad}

La perspectiva relacional nos abre la posibilidad de analizar al turismo como una práctica de semiosis social, en donde los hábitos y prácticas dejados por el periodo de pandemia van a tener efectos duraderos. Así, sugeriría en algún ejercicio futuro analizar las características de heterogeneidad, multilocalidad, globalidad, diversidad extrema de prácticas y civilización que plantean Darbellay y Stock (ibid) para retomar un aspecto que dichos autores no abordan: el tema del poder y los derechos ciudadanos. En el periodo post-Covid, habría que recuperar las experiencias del turismo creativo y regenerativo, para establecer una relación de colaboración entre huéspedes y anfitriones. ¿Por qué? Porque la subordinación de las sociedades anfitrionas altamente dependientes del turismo, las coloca en una situación de vulnerabilidad. En caso de nuevas pandemias, se verían obligadas a rebajar los estándares de cuidados de su población en los casos de pandemia y otras catástrofes similares.

Después del confinamiento, habrá que considerar que el turismo puede avanzar por el sendero del giro recreativo. Podemos visitar nuestros museos, centros históricos, zonas arqueológicas en nuestra misma ciudad, y ver con nuevos ojos aquello que para nosotros es ya muy visto.

\section{Conclusiones}

La llegada de la pandemia afecto al turismo y llevó a cuestionar el modelo de turismo de masas y alta movilidad. Este tipo de turismo que ha crecido a expensas del medio ambiente y la explotación de los trabajadores del turismo. Los estudiosos consideraron que habría que repensar el tipo de desarrollo del turismo después de la pandemia y apostar por modelos sustentables, más accesibles a la población local, respetuosos del medio ambiente.

En México, la promoción del turismo de masas privilegió los destinos de sol y playa, cuyo modelo es altamente polarizante y excluyente, pues se sustenta en la acumulación por desposesión de grandes franjas de litoral, la genera urbanizaciones sin ciudad, sin espacios para el recreo y la convivencia. Se trata de un modelo que genera regiones altamente dependientes de la llegada de turistas internacionales y que se tornan muy vulnerables ante la llegada de nuevas pandemias. 
En un continuum que va de la más alta a la más baja dependencia del turismo, los destinos de todo el mundo han sido afectados por la pandemia, pero esta afectación se acentúa en espacios urbanos mono-funcionales "desde Las Vegas a Cancún, Bávaro, Hawaii, o Bali” (Blázquez, 2020). Por ello, se abre la necesidad de plantear escenarios turísticos alternativos, tales como el redescubrimiento del territorio, guiados por la proximidad. Ciudades, como la de México, con su amplia oferta cultural es un espacio ideal para llevar a cabo dicho redescubrimiento. Blázquez advierte que la era de la hiper-movilidad se desvanece y, en ese sentido, la tendencia es a la desglobalización. Esto parece ser verdad en lo inmediato, junto con la promoción del turismo de proximidad.

Por ahora y a reserva de hacer un balance, cabe señalar que durante el confinamiento y la parálisis de la Ciudad de México, la pandemia dejó sin empleo a más de un millón de personas que laboran en hoteles y restaurantes. Impactó en las 786 agencias de viajes que estaban registradas en 2019; dejó sin trabajo a 544 guías de turistas; a 886 establecimientos de alimentos y bebidas, y a 25 empresas dedicadas al turismo alternativo. Paralizó 30 rutas, circuitos y recorridos turísticos, además del cierre de los cines, teatros, museos, auditorios, centros de convenciones, suspensión de festivales, espectáculos, congresos académicos y una amplia gama de actividades culturales y recreativas.

Habría que pensar, por tanto, en la necesidad de fortalecer el "giro recreativo" que el turismo ha generado a través del turismo de cercanías, la revaloración de la propia ciudad, la apropiación por parte de la ciudadanía del patrimonio cultural, así como las prácticas del turismo creativo y regenerativo para hacer de las ciudades espacios tolerantes, democráticos y plurales. Algunas de esas enseñanzas habría que obtener de la pandemia.

\section{Referencias}

Alvarado-Sizzo, Illia, Álvaro López y Fernando Zamora. 2020. “La imagen y la representación en el turismo de la pomodernidad" en Hiernaux-Nicolas, D., M. Osorio y R.A. Vázquez, Los imaginarios sociales y el turismo: conceptos y aplicaciones, U. Panamericana, Campus México.

Appadurai, Arjun D. 1990. "Disjuncture and difference in the global cultural economy” (1990). Culture Society 1990; 7; 295. 
Blázquez, Macià. 2020. "La crisis de la COVID-19 no es decrecimiento, es una catástrofe", entrevista de Ginard A. y Verger, P. 17 de abril de 2020, en UH Noticias, El Económico.

https:/www.ultimahora.es/noticias/economico/2020/04/17/1157985/macia-blazquez-apuesta-por-decrecimiento-turistico-asegura-tarde-temprano-nos-teniamos-pegar.html\#tabs-media-video (Consultado el 15 de febrero de 2021)

Cañada, Ernest e Ivan Murray. 2021. \#PostCovid19, Turistificación confinada. Alba Sud Editorial, colección turismos, número 7.

Darbellay, Frédéric y Mathis Stock. 2012. "Tourism as complex interdisciplinary research object" Annals of Tourism Research, Vol. 39, No. 1 pp. 441-458.

Delgadillo, Víctor M. 2009. "Patrimonio urbano y turismo cultural en la Ciudad de México: Las chinampas de Xochimilco y el Centro Histórico", Andamios, Volumen 6, número 12, diciembre, 2009, pp. 69-94.

De Mauleón, Héctor. 2015. "La ciudad de los palacios", Nexos, 25 de abril de 2015 .

Díaz, Ibán y Luis A. Salinas. 2016. "La producción del consumidor. Valorización simbólica y gentrificación en el centro de la Ciudad de México", Andamios, Volumen 13, número 32, septiembre-diciembre, 2016, pp. 107-130

Duxbury, Nancy \& Greg Richards. 2019. "A Research Agenda for Creative Tourism”, Cidades [Online], No. 40 | 2020, 24, julio 2020, http:// journals.openedition.org/cidades/2576

Duxbury, Nancy, F. Bakas, T. V. Castro, S. Silva. 2020. Palavras para lá da pandemia: cem lados de uma crise. Turismo Recreativo. Centro de Estudos Sociais, Universidad de Coimbra, Portugal.

Gobierno de la Ciudad de México, 2021, Secretaría de Turismo, Capital LGBTTTI, Guía de la Diversidad de la Ciudad de México.

http://cdmxtravel.com/assets/uploads/documents/guia-lgbt-espa\%C3\%B1ol. pdf (consultado el 29 de marzo de 2021)

Gobierno de la Ciudad de México (2020/a, Secretaría de Turismo. Anuario estadístico de Turismo 2020.

https://www.turismo.cdmx.gob.mx/storage/app/media/Docs/Anuario\%20 estadistico\%20Turismo\%2020.pdf (consultado el 28 de marzo de 2021). 
Gobierno de la Ciudad de México, 2020/b, Secretaría de Turismo, Actividad turística de la Ciudad de México, enero - diciembre 2010 - 2020, en file:///Users/oehichen1/Documents/SECTUR/12\%20Indicadores\%20Diciembre\%202020.pdf

Gössling, Stefan, Daniel Scott \& C. Michael Hall. 2021. "Pandemics, tourism and global change: a rapid assessment of COVID-19", Journal of Sustainable Tourism, 2021, Vol. 29, No. 1, 1-20

Hall, Michael C., Daniel Scott \& Stefan Gössling. 2020. "Pandemics, transformations and tourism: be careful what you wish for", Tourism Geographies, Vol. 22, No. 3, 577-598

Hiernaux, Daniel y Carmen Imelda González. 2015. "Patrimonio y turismo en centros históricos de ciudades medias. ¿Imaginarios encontrados?", URBS. Revista de Estudios Urbanos y Ciencias Sociales, Vol. 5, No. 2, 111-125

INEGI 2020, Cuenta satélite del turismo en México, 2019. Diciembre 15 de 2020. Consultado el 13 de marzo de 2021 en

https://www.inegi.org.mx/contenidos/saladeprensa/boletines/2020/StmaCntaNal/CST2019.pdf

INEGI 2021. Temas, turismo. Información General, Tabulados https://www. inegi.org.mx/temas/turismo/\#Informacion_general

López, Álvaro y Rosaura Carmona. 2008, “Turismo sexual masculino-masculino en la Ciudad de México", Teoría y Praxis, núm. 5, 2008, pp. 99-112.

Milano, Claudio y José Mansilla (coords). 2018. Ciudad de vacaciones. Conflictos urbanos en espacios turísticos, Barcelona.

Murray, Ivan y Ernest Cañada. 2021. "Turistificación confinada", en E, Cañada e I. Murray (ed.) TourismPostCOVID19, Turistificación confinada, Alba Sud Editorial, Colección Turismos, núm. 7, 2021.

Moranta, Joan. 2021. "La vulnerabilidad de la especialización turística", en E. Cañada e I. Murray, \#PostCovid19, Turistificación confinada. Alba Sud Editorial, colección turismos, pp. 82-87

Nepal, Sanjay K. 2020. “Adventure travel and tourism after COVID-19 business as usual or opportunity to reset?", Tourism Geographies, Vol. 22, No. 3, 646-650

Nicosia, Enrico. 2018. "La Sicilia del Comisario Montalbano: de la narración literaria a la transposición televisiva. Un caso exitoso (cine) turístico internacional", Polígonos, Revista de Geografía, 30: 49-76.

Niewiadomski, Piotr. 2020. "COVID-19: from temporary de-globalisation to a re-discovery of tourism?", Tourism Geographies, vol. 20, No. $3,651-656$ 
Oehmichen, Cristina y Consepción Escalona. 2021. "El COVID-19 en Cancún: epidemia y vulnerabilidad en un destino turístico de clase mundial", en E, Cañada e I. Murray (ed.) TourismPostCOVID19, Turistificación confinada, Alba Sud Editorial, Colección Turismos, núm. 7, 2021.

Richards, Greg. 2001. "El desarrollo del turismo cultural en Europa", Estudios Turísticos, n. ${ }^{\circ} 150$ (2001), pp. 3-13

Sánchez, Álvaro y Álvaro López (2000) "Visión geográfica de los lugares gays de la Ciudad de México”. Cuicuilco, Vol. 18, núm. 7, pp. 271286.

Secretaría de Salud. 2021, Información referente a casos de Covid 19 en México. Gobierno de México, https://datos.gob.mx/busca/dataset/ informacion-referente-a-casos-covid-19-en-mexico

SECTUR. 2020. Programa sectorial de turismo 2020-2024. Gobierno de México, Secretaría de Turismo.

http://sistemas.sectur.gob.mx/SECTUR/PROSECTUR_2020-2024.pdf, consultado el 12 de febrero de 2021

SECTUR. 2021. Avance y resultados 2020. Programa derivado del Plan Nacional de Desarrollo 2019-2024. Programa Sectorial de Turismo 2020-2024. Gobierno de México, Secretaría de Turismo, 14 de mayo de 2021.

https://www.gob.mx/cms/uploads/attachment/file/637501/avance-resultados-2020-prosectur.pdf

Urry, John. 2002. The tourist gaze. Londres, Sage Publications 
